\title{
Pena de muerte a la pena de muerte*
}

\author{
José Russo Delgado
}

\section{Humanitarismo}

Con frecuencia se habla de humanitarismos positivistas, materialistas, etc.: el término ha llegado a ser despectivo. Y parece haber un terrible malentendido cuando se atribuye a humanitarismos de tal o cual especie los argumentos en contra de la pena de muerte: estos no serían sino expresión de determinado humanitarismo, no tendrán mayor valor.

Humanitarismo es "ismo" de humanidad, de lo que caracteriza al hombre, de lo que el hombre es. Si en cuanto "ismo" puede acusar exceso, y aun, acaso, desviación, hay que no perder de vista este algo valioso que en él puede sobrepasarse o desviarse. Un humanitarismo positivista podría, pongamos por caso, no estar en lo justo en cuanto positivista ni quizá en cuanto humanitarismo pero si al poner de relieve lo que espropio del hombre, el sentimiento de comunidad, de unidad humana. El humanitarismo positivista, cualquier humanitarismo tienen así un elemento que podemos llamar religioso, un elemento que es la religión misma si religión -como lo decía Tolstoies todo aquello que une a los hombres. Entonces cada vez que, sobre todo, desde un punto de vista al parecer religioso se consideran despectivamente los humanitarismos, hay un vicio radical en la actitud, que resulta a fin de cuentas semejante a la de los dictadores cuando hablan de democracia y acusan de intentos dictatoriales a una oposición efectivamente democrática.

\section{Zoologia}

Forma parte de ese elemento de verdad humana que hay en todo hombre el sentimiento de comunidad humana, de unidad esencial con los

* El presente artículo fue publicado en Germinal. Revista Universitaria, UNMSM, Año 3, julio-agosto de 1960, pp. 3 y 12.

LETRAS (Lima), 94: 55-58,1997. 
más hombres: un hombre no es una isla ni una perla en un collar que pueda separase o bien ser de este collar y no del otro: todos los hombres vivimos la aventura del hombre, la aventura de la existencia humana. La familia humana es una realidad y es una, aunque las superestructuras políticas y económicas no coincidan, por desgracia, con ella.

El sentimiento de fraternidad humana es justamente destacado en mil formas en los ideales más opuestos; para un gran pensador contemporáneo es por ejemplo fundamental en la democracia, pues sólo la fraternidad -dicc- permite la conciliación entre la libertad y la igualdad. Sin ella una de estas destruiría a la obra y se destruiría la democracia.

El hombre tiene que mentirse a sí mismo para víctimar al hombre, tiene que olvidarse de que a quien va víctimar es a un hombre; resulta revelador que la prensa, la radio, etc., preparen en cierta forma la aplicación de la pena de muerte hablando de "hienas", "monstruos", etc. Pero, no, esos desdichados siguen siendo seres humanos pese a sus repulsivos delitos.

Quien quiere la muerte de otro se pone en los ojos una venda semejante a la que se ofrece al reo en el momento de ser ajusticiado: se niega a ver un ser humano en el objeto de su afán homicida, al que se iguala, cabalmente en lo que tienededhomicidac queriendo ét también una muerte.

Yerro "Jorge Puccinelli Converso"

El argumento decisivo en favor de la pena de muerte, que sirve para impedir que se cometan crímenes no se ve confirmado por los hechos, las estadísticas no revelan el valor de escarmiento de la pena de muerte. Algunos datos: en los Estados Unidos, el Estado de Winsconsin, donde la pena de muerte fue, abolida desde 1854, es uno de los de más bajo índice de criminalidad, y si bien otro Estado donde tampoco hay ejecuciones desde 1847 como Michigan exhibe un índice de criminalidad relativamente alto, en Illinois, Estado vecino del último en que sí se aplica la pena de muerte, el porcentaje es más alto todavía. Los ejemplos podrían multiplicarse.

Cuando allá por el año de 1800 se colgaba a los carteristas en Inglaterra, ocurría a menudo que el acto público en que el carterista era ahorcado provocaba un gran concurrencia en que los carteristas hacían su agosto: los 
carteristas ejercían sus actividades durante el ahorcamiento de carteristas que habían ejercido sus actividades durante el ahorcamiento, etc.

Estadísticas y hechos como los anteriores, de permitir llegar a una conclusión mostrarían que la pena de muerte es inconveniente, que con ella se obtiene lo contrario de lo que se desea. Si se prefiere no llegar a conclusión alguna porque las estadísticas son en verdad, dudosas ¿por qué aplicar castigo semejante, irreparable en caso de un error?

\section{Negocio}

En cuanto a la actitud de la prensa en general favorable a la pena de muerte hay que reconocer que los ajustamientos permiten un incremento de circulación y que los intereses económicos al parecer son siempre respetables. (Los intereses puramente humanos pueden en cambio considerarse "sentimentalismo", humanitarismo", "positivismo", acaso comunismo).

No importa que no sean públicos los ajusticiamiento, la espectacularidad de que se les rodea resulta atractiva en grado sumo para la morbosa vanidad de los delicuentes. Por lo demás, la aplicación de la pena de muerte resulta tan poco ejemplarizadore eome eseéastige que por lo regular reciben al final, sólo al finaldelexualidad ilíciţ \&lacviolencia en las películas -americanas o no- que casi sin excepción no constituyen otra cosa que una incitación constante justo a la sexualidad ilícita y la violencia.

\section{Frustración}

La psicología nos enseña que cuando ocurre una frustración surge la tendencia a adoptar formas regresivas de conducta, más primitivas y menos inteligentes, a volver a antiguas, supuestas soluciones que resultaron ineficaces. Cuando se producen olas de crímenes en una sociedad, se experimenta ese sentimiento de frustración y surge tal tendencia que a menudo se abre paso y termina por triunfar, como sucedió entre nosotros con la reimplantación de la pena de muerte. Esta aparece como respuesta al clamor "hay que hacer algo", así sea tomar medidas ineficaces y hasta contraproducentes que en el fondo sólo satisfacen oscuros, irracionales sentimientos de compensación semejantes a los que ocasionan los crímenes más exe- 
crables. Pero la pena de muerte no es, como se creyera, como se quisiera creer, medio de evitar tales crímenes.

Forma parte de la psicología del castigo obtener resultados pasajeros y nada más; apenas se borra la impresión del castigo los antiguos hábitos e inclinaciones vuelven a hacerse presentes y predominar. La pena capital, además, ejerce una fascinación morbosa, expresión extrema del impulso subconsciente de realizar aquello que se teme -el de los raterillos de hace siglo y medio en Inglaterra- que se da paradojalmente unida a la confianza del delicuente en poder burlar la ley.

Que mienta el delicuente para tratar de defenderse es cosa que debe esperarse, pero no dejemos que la sociedad mienta -o se engañe así misma, para el caso da igual- hablando de la eficacia de la pena de muerte. En este caso se confirma también el bíblico acompañamiento de la mentira por el homicidio, aunque se trate ahora de un homicidio cometido por el Estado y no previsto en la respectiva figura delíctiva del Código Penal.

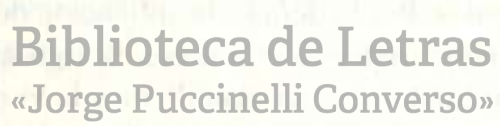

